\title{
Title: COSTS OF STRIKES BETWEEN VULNERABLE MISSILE FORCES
}

Author(s):

Gregory H. Canavan, DDP

Submitted to:

For discussions outside the Laboratory

Date: February 1997

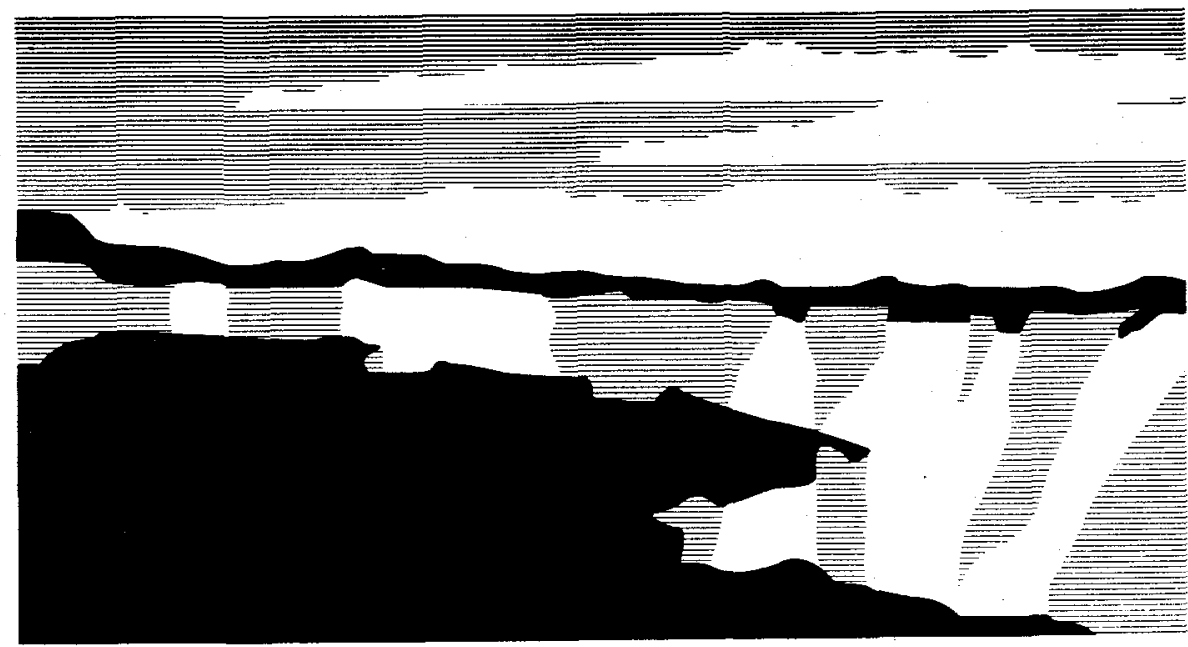

Los Alamos National Laboratory, an affirmative action/equal opportunity employer, is operated by the University of California for the U.S. Department of Energy under contract W-7405-ENG-36. By acceptance of this article, the publisher recognizes that the U.S. Government retains a nonexclusive, royalty-free license to publish or reproduce the published form of this contribution, or to allow others to do so, for U.S. Government purposes. The Los Alamos National Laboratory requests that the publisher identify this anicle as work performed under the auspices of the U.S. Department of Energy. 


\section{DISCLAIMER}

This report was prepared as an account of work sponsored by an agency of the United States Government. Neither the United States Government nor any agency thereof, nor any of their employees, make any warranty, express or implied, or assumes any legal liability or responsibility for the accuracy, completeness, or usefulness of any information, apparatus, product, or process disclosed, or represents that its use would not infringe privately owned rights. Reference herein to any specific commercial product, process, or service by trade name, trademark, manufacturer, or otherwise does not necessarily constitute or imply its endorsement, recommendation, or favoring by the United States Government or any agency thereof. The views and opinions of authors expressed herein do not necessarily state or reflect those of the United States Government or any agency thereof. 


\section{DISCLAMMER}

Portions of this document may be illegible in electronic image products. Images are produced from the best available original document. 


\title{
COSTS OF STRIKES BETWEEN VULNERABLE MISSILE FORCES
}

\author{
Gregory H. Canavan
}

This note derives the first and second strike magnitudes and costs for strikes between vulnerable missile forces with multiple warheads. The extension to mixes with invulnerable missiles is performed in a companion note. Stability increases as the number of weapons per missile is reduced. The optimal allocation of weapons between missiles and value is significant in predicting the stability impact of the reduction of the number of weapons per missile at large numbers of missiles, less significant in reducing the number of missiles for fixed weapons per missile. At low numbers of missiles, the stability indices for singlet and triplet configurations are comparable, as are the number of weapons each would deliver on value targets.

This note derives the first and second strike magnitudes and costs for strikes between vulnerable missile forces with multiple warheads. The extension to mixes with invulnerable missiles is performed in a companion note. The model's exchange equations are derived in companion papers, which are reviewed. The costs of striking first and second are measured in terms of the physical damage. The two main objectives in those exchanges are to minimize the damage inflicted on oneself and to retain the ability to inflict damage on the other. It is assumed that the offensive forces of each side are comparable in size and capability. Costs to self and other are combined into costs for striking first and second, whose ratio is the overall stability metric. Stability is predicted to increase as the number of weapons per missile or the kill probability per weapon is reduced. It is relatively insensitive to the relative preference for inflicting damage to the other and reducing damage to self. The optimal allocation of weapons between missiles and value is significant in predicting the stability impact of the reduction of the number of weapons per missile at large numbers of missiles, less of an issue in reductions of the number of missiles for fixed numbers of weapons per missile. At 100 missiles, the stability indices for singlet and triplet configurations are comparable, as are the number of weapons each would deliver on value targets.

Review of earlier results. It is possible to model exchanges between symmetric, vulnerable missiles forces in terms of the first, $\mathrm{F}$, and second, $\mathrm{S}$, strikes that either side could deliver. For a force of $\mathrm{M}$ missiles with $\mathrm{m}$ weapons each, of which a fraction $\mathrm{f}$ are directed at the opponent's missiles, the first strike on value targets is

$$
F=(1-f) m M \text {. }
$$

Thus, the average number of weapons delivered on each missile is

$$
\mathrm{r}=\mathrm{fmM} / \mathrm{M}=\mathrm{fm} \text {. }
$$

Interest here is on $r$ large, so that the average probability of survival can be approximated by 1 


$$
\mathrm{Q} \approx \mathrm{q}^{\mathrm{r}} \text {, }
$$

where $q=1-p$ and $p$ is the attacking missile's single shot probability of kill. The second strike is

$$
\mathrm{S}=\mathrm{mMQ} \approx \mathrm{mMq}^{\mathrm{r}} \text {, }
$$

all of which is delivered on value targets, because missiles remaining at the end of the exchange are taken to have no value-although that assumption is simple to remove. ${ }^{2}$

Costs. Earlier notes have used linearized costs to simplify analytic discussions. This section derives appropriate first and second strike costs for large forces. The costs of striking first or second are measured in terms of the physical damage done to one's opponent and self in such strikes. The two main objectives in those exchanges are to minimize the damage inflicted on oneself and to retain the ability to inflict damaging on the other, in order to deter his action. In the former, the relevant cost is the imperfect denial of damage to self. For the latter, the cost is the portion of one's damage objectives one is unable to achieve. Costs are thus measured by the adequacy of delivered first and second strikes relative to cumulative value functions.

It is assumed below that the offensive forces of each side are comparable in size and capability, so the same set of parameters apply to both. Current offensive forces and target sets are not completely symmetric, but earlier calculations have shown that the trends from calculations that ignore the modest current asymmetries correctly retain the major trends and results seen in more detailed calculations. ${ }^{3}$ Thus, this assumption retains the main structure of the full exchange while making the calculations and results simpler to explain and explore. The extension of the forces and stability metrics to non symmetrical forces is derived in the companion paper. ${ }^{4}$

First strike. Let $\mathrm{k}$ be a constant that is numerically about equal to the inverse of the size of the value target sets held at risk. Then the normalized cost to self (s) for the side that strikes first (1) can be approximated by

$$
\mathrm{C}_{1 \mathrm{~s}}=1-\mathrm{e}^{-\mathrm{kS}} \text {, }
$$

because the first striker only has to absorb the other side's second strike, $\mathrm{S}$. This form of $\mathrm{C}_{1 \mathrm{~s}}$ is simple, but not unique. Its variation with $\mathrm{S}$ and $\mathrm{k}$ is plausible, and it exhibits diminishing returns, being perhaps the simplest form that does so. More detailed specification of the cost would require details about preferences, priorities, and deterrents that are not known or knowable. For $\mathrm{S}$ small relative to the size of the target set, $1 / \mathrm{k}$, the cost for damage to self is $\approx \mathrm{kS}$, as assumed in earlier notes. ${ }^{5}$ For $\mathrm{S}$ large, i.e., a small or ineffective first strike, $\mathrm{C}_{1 \mathrm{~s}}$ rises to unity, although its normalization is arbitrary. The cost of incomplete realization of one's damage objectives on the other can be approximated by

$$
\mathrm{C}_{10}=\mathrm{e}^{-\mathrm{kF}} \text {. }
$$

If $\mathrm{F}$ is small, an ineffective first strike, the cost is roughly unity, because it achieves little of the first striker's objectives. If $F$ is large compared to $1 / k, C_{10}$ drops to $\approx 0$. 
The cost of damage to self and of incomplete damage to the other are incommensurate, because they are fall on different parties. Thus, they are not formally a sound basis for decisions by either. Theoreticians have worked with partial success on how to combine them. A simple prescription is to take their weighted sum 6

$$
\mathrm{C}_{1}=\left(\mathrm{C}_{1 \mathrm{~s}}+\mathrm{L} \mathrm{C}_{10}\right) /(1+\mathrm{L})=\left(1-\mathrm{e}^{-\mathrm{kS}}+\mathrm{Le} \mathrm{e}^{-\mathrm{kF}}\right) /(1+\mathrm{L}),
$$

where $\mathrm{L}$ is a constant. Choosing $\mathrm{L}$ small means $\mathrm{C}_{1} \approx \mathrm{C}_{1 s}$, so the first striker is primarily concerned about denying damage to self. Choosing $L$ large means $C_{1} \approx C_{10}$, so he is more interested in inflicting damage on the other. It is generally assumed that $\mathrm{L} \leq 1$, although there is no fundamental reason that has to be so.

This construction of $\mathrm{C}_{1}$ as a weighted averages of the cost to self and other is plausible, but not unique. The costs could instead be based on the product or powers of the costs to self and other. The advantage of the weighted average is that it is simple and that it reduces all of these complications to the choice of $L$. The sensitivity of results to $L$ has been examined separately. 7

Second strike costs are evaluated similarly. The normalized cost to self for the second striker, who must ride out the undiminished first strike $F$, is

$$
\mathrm{C}_{2 \mathrm{~s}}=1-\mathrm{e}^{-\mathrm{kF}} \text {, }
$$

which is $\approx 1$ for $F$ large, when his loss is near total, and $\approx k F$ for $F<<1 / k$. The cost of the second striker's partial pursuit of his damage objectives with his diminished force $S$ is

$$
\mathrm{C}_{20}=\mathrm{e}^{-\mathrm{kS}} \text {, }
$$

which is small for $S$ large and $\approx 1$ for $S \ll 1 / k$. If these two types of costs are weighted with the same constant $L$ used above, the total cost of striking second is

$$
\mathrm{C}_{2}=\left(1-\mathrm{e}^{-\mathrm{kF}}+\mathrm{L} \mathrm{e}^{-\mathrm{kS}}\right) /(1+\mathrm{L}) \text {. }
$$

Stability Indices. To summarize, the exchange calculations determine the $F$ and $S$ of Eqs. (1) and (4). They in turn determine the $C_{1}$ and $C_{2}$, of Eqs. (7) and (10), which must be converted into an index of stability. There is additional arbitrariness in converting $C_{1}$ and $C_{2}$ into stability indices. Three current choices of indices are the ratio of $\mathrm{C}_{1} / \mathrm{C}_{2}$, the difference $\mathrm{C}_{2}$ $\mathrm{C}_{1}$, and $\mathrm{C}_{2}$ alone. It is shown elsewhere that the first two, which are the primary ones used in U.S. analyses, generally give similar results, but that the third, which is used mutual assured destruction (MAD) and some Russian analyses, gives results which disagree strongly with the first two and have logical inconsistencies for important combinations of $F$ and $S .{ }^{8}$ The reasons for and consequences of these differences have been explored adequately elsewhere and are not essential to the discussion of stability issues below. For small forces the ratio and difference of cost give similar trends, while the latter are simpler to investigate analytically, so the difference of cost was used in some earlier discussions of metric issues. For large forces, the ratio of costs gives interesting new insights, so the ratio metric is discussed here. 
The ratio of costs usually considered is $C_{1} / C_{2}$. If the cost of striking first, $C_{1}$, is large, the first striker should be deterred from initiating an exchange. Similarly, if the cost of striking second, $\mathrm{C}_{2}$, is small, both sides should see little penalty in riding out a crisis. Thus, the ratio $\mathrm{C}_{1} / \mathrm{C}_{2}$ captures both of these influences in a single number or stability index

$$
\mathrm{I}=\mathrm{C}_{1} / \mathrm{C}_{2}=\left(1-\mathrm{e}^{-\mathrm{kS}}+\mathrm{Le}-\mathrm{kF}\right) /\left(1-\mathrm{e}^{-\mathrm{kF}}+\mathrm{Le}-\mathrm{kS}\right)
$$

For $\mathrm{F}$ and $\mathrm{S}$ small, the stability index reduces to

$$
\mathrm{I}(\mathrm{small} \mathrm{F}, \mathrm{S}) \approx[1-\mathrm{k}(\mathrm{F}-\mathrm{S} / \mathrm{L})] /[1-\mathrm{k}(\mathrm{S}-\mathrm{F} / \mathrm{L})] \text {. }
$$

For $L$ large, i.e., aggressive competitors, this reduces to $(1-\mathrm{kF}) /[1-\mathrm{kS}) \approx 1-\mathrm{k}(\mathrm{F}-\mathrm{S})$. $\mathrm{F}$ is generally larger than $\mathrm{S}$, so the index is less than unity in proportion to their difference. For $\mathrm{L}$ small, conservative competitors, this reduces to $\mathrm{kS} / \mathrm{L} / \mathrm{kF} / \mathrm{L}=\mathrm{S} / \mathrm{F}$, which again gives an index is less than unity and proportional to the ratio of $\mathrm{S}$ to $\mathrm{F}$. For $\mathrm{S}$ and $\mathrm{F}$ large, I approaches unity.

Results. The above equations constitute a closed model that can be solved to predict the variation of $\mathrm{C}_{1}, \mathrm{C}_{2}$, and $\mathrm{I}$ with the principal model parameters, which are $\mathrm{M}, \mathrm{m}, \mathrm{p}, \mathrm{L}$, and $\mathrm{f}$.

Number of weapons per missile (MIRV ratio). Figure 1 shows $\mathrm{C}_{1}, \mathrm{C}_{2}$, and $\mathrm{I}$ as functions of the number of weapons per missile for $M=1000$ missiles with $p=0.6,60 \%$ of which are allocated to value, ant $1 / k=1,000$ value targets. For large MIRV ratios, $C_{2}$ is large because few missiles survive to retaliate, $\mathrm{C}_{1}$, is small because little retaliation is met, and the index $\mathrm{I}$ is very small. As the number of MIRVs decreases, $\mathrm{C}_{2}$ decreases and $\mathrm{C}_{1}$ increases, so I increases, reaching unity at about 2 weapons per missile. For smaller MIRV ratios, there are too few RVs to cover the attacked missiles, so S, $\mathrm{C}_{1}$, and I increase rapidly.

Allocation of weapons to missiles. Figure 2 shows the variation of $\mathrm{C}_{1}, \mathrm{C}_{2}$, and I with the fraction of the strike on value, $f$, for $1,0003-\mathrm{MIRV}$ missiles with $\mathrm{p}=0.6$ on 1,000 value targets. In contrast to the solution to the linearized equations for low force levels, ${ }^{9} \mathrm{C}_{1}$ and $\mathrm{C}_{2}$ have extrema in the interior of the interval rather than at $\mathrm{f}=0$ or $1 . \mathrm{C}_{2}$ has a maximum of about 0.65 at $f=0.5$, and $C_{1}$ has a minimum of about 0.4 at $f=0.7$. Their ratio gives an index with a minimum of about 0.6 at about 0.6 . As discussed elsewhere, if he decided to initiate an exchange, the first striker would attempt to minimize the damage to himself, $\mathrm{C}_{1}$. Thus, he should operate at $\mathrm{f} \approx 0.7$, at which the cost to the attacked side would be $\mathrm{C}_{2} \approx 0.7$, and the overall index would be about 0.6. Note that the value of the index that results from the attacker's optimization of $f$ does not correspond to a minimum or maximum of $\mathrm{C}_{2}$ or I. Note also that $\mathrm{f} \approx 0.7$ is optimum for the MIRV ratio $=3$ point of Fig. 1, but is not optimal for other values, as discussed elsewhere.

Relative preference for damage to other. Figure 3 shows the variation of costs and indices with the relative preference for inflicting damage on others and denying it to oneself, $\mathrm{L}$, for 1,000 $p=0.63$ MIRV missiles. There is little variation of costs or indices with $L$ for these conditions. $\mathrm{C}_{1}$ is about $0.6 \mathrm{C}_{2}$ and $\mathrm{I}$ is about 0.6 throughout. There is a stronger variation for fewer or singlets missiles, which is better discussed in conjunction with survivable forces. 
Weapon kill probability. Figure 4 shows the variation of the costs and indices with kill probability $\mathrm{p}$ for 1,000 triplet missiles. For large $\mathrm{p}, \mathrm{C}_{2} \approx 0.7, \mathrm{C}_{1} \approx 0.2$, and the index is $\approx 0.25$. As $p$ falls, $C_{2}$ falls, $C_{1}$ increases, and the index reaches unity at $p \approx 0.4$. For smaller $p, I$ is well above 1 . However, the current range is probably about $p=0.6$ to 0.8 , which would be in a region with I well below unity. It is useful to note, however, that the range $p=0.6$ to 0.8 , the costs and indices are not strongly dependent on $\mathrm{p}$.

Optimization of weapon allocation (minimization of $\mathrm{C}_{1}$ ). Figure 5 shows the variation of the costs and indices with the MIRV ratio for allocations of weapons to value that minimize $\mathrm{C}_{1}$ at each value of the ratio. It is useful to compare this result, which treats the same number of missiles and MIRVs with a constant value of $f=0.7$. Optimizing the attack increases $C_{2}$ and decreases $\mathrm{C}_{1}$ slightly, so that the stability index only reaches unity for singlets rather than the doublets of Fig. 1. The component cost of $\mathrm{C}_{1}$ and $\mathrm{C}_{2}$ are shown in Fig. 6 . The bottom two curves are the costs for damage to self $\mathrm{C}_{1 \mathrm{~s}}$ and incomplete damage to other $\mathrm{C}_{10}$ of Eqs. (8) and (9). They start out at low levels at large MIRV ratios, where the attacker can thoroughly suppress the other side's retaliatory force. The top two curves are for the attacked sides damage to self $\mathrm{C}_{2} \mathrm{~s}$ and other $\mathrm{C}_{20}$ from Eqs. (8) and (9). They start at relatively high levels due to the large damage on the attackee's value and weak retaliation. As the MIRV ratio decreases, the two costs join at singlets, where the damage to self from striking first is about equal to that from striking second $\left(\mathrm{C}_{1 s} \approx \mathrm{C}_{2 s}\right)$ and the cost of damage not done to the other is about the same whether one strikes first of second $\left(\mathrm{C}_{10} \approx \mathrm{C}_{20}\right)$.

Figure 7 shows the optimal allocation of 1,000 triplet first strike missiles on 1,000 silos and 1,000 value targets. For large MIRV ratios, the optimal value is about 0.65 . For intermediate $\mathrm{m}$ it rises to about 0.7 , the value used in some calculations above. However, for MIRV ratios below triplets, the fraction allocated to missiles begins to fall, reaching about 0.25 for singlets. For large ratios, the attacker can suppress the retaliatory strike with a modest fraction of his force. For small ratios, the retaliatory missiles are no longer strongly covered, their survival probability begins to rise, and the attacker is forced to shift weapons from value to missiles, leading to the decrease in f. Fig. 6 shows that the first striker's cost of damage self increases most sharply as $m$ decreases in the range of MIRV ratios from 3 to 2 , which is why the decrease in $f$ is sharpest there to destroy missiles and minimize damage to self. Capturing this sharp decrease in $f$ is an essential part of the analysis of the benefits of de-MIRVing.

Number of missiles. Figure 8 shows the optimal allocation of weapons to missiles as each side's total number of missiles is decreased from 900 to 100 . The top curve is for triplet missiles. If falls from $f \approx 0.7$ at 900 missiles to $f \approx 0.55$ at 100 missiles. The drop is sharp, but not as pronounced as the decrease from 3 to 1 weapon per missile at 1,000 missiles. The bottom curve is for singlets. It increases from about 0.25 to 0.3 . At 100 missiles, these allocations would give $\approx$ 
$0.5 \times 3 \times 100 \approx 150$ weapons on value for triplets and $\approx 0.7 \times 1 \times 100 \approx 70$ weapons on value for singlets. Thus, to the extent that the value targets contain other than purely military targets, the two configurations only lead to a factor of two difference in the number of weapons on them.

Figure 9 shows the costs and stability indices for singlets and triplets. The top curve is the stability index for singlets, which is about unity throughout. The next curve down is the stability index for triplets, which is about a factor of two lower at large $\mathrm{M}$, but is with about $10 \%$ of the index for singlets at 100 missiles. The lower curves are for costs. For singlets, the first and second strikes are about the same, which is why their index is near unity. For triplets, they differ significantly for large $\mathrm{M}$, but converge with each other-and with the costs for the singlets-by about $M=100$, which is why the triplet index climbs rapidly towards unity there. That the singlets' index approaches unity is just a specific example of the generally believed result that symmetric singlet configurations are crisis stable. That the triplets' index also approaches unity is a result of the optimal allocation of weapons away from missiles.

The one other parameter in this model is $\mathrm{k}$, which characterizes the size of the value target set. However, $\mathrm{F}$ and $\mathrm{S}$ and both proportional to $\mathrm{M}$, and the costs depend on $\mathrm{kF}$ and $\mathrm{kS}$; thus, decreasing $\mathrm{M}$ has the same effect as decreasing $\mathrm{k}$, i.e., increasing the size of the value target set, so it is not mathematically necessary to vary $\mathrm{k}$ separately. However, since offensive forces are strategic weapons and the value targets are largely non-strategic targets, this interpretation would appear to couple reductions in strategic and non-strategic forces.

Summary and conclusions. This note derives the first and second strike levels and costs for exchanges between vulnerable, multiple warhead missile forces. The extension to mixes with invulnerable missiles is performed in a companion note. The model's exchange equations are derived in companion papers, the results of which are reviewed. The costs of striking first and second are measured in terms of the physical damage done to one's opponent and self in such strikes. The two main objectives in those exchanges are to minimize the damage inflicted to oneself and to retain the ability to inflict damage on the other, in order to deter his action. In the former, the relevant cost is the imperfect denial of damage to self; in the latter it is the cost of imperfect achievement of damage objectives to the other. It is assumed below that the offensive forces of each side are comparable in size and capability.

Costs to self and other are combined into costs for striking first and second, whose ratio is the overall stability metric. Stability is predicted to increase with a reduction in the number of weapons per missile or the kill probability per weapon. Stability is relatively insensitive to the two sides' relative preference for inflicting damage to the other and reducing damage to self. The optimal allocation of weapons between missiles and value is a key feature in predicting the impact on stability of the reduction of the number of weapons per missile at large numbers of missiles. It is somewhat less of an issue in strong reductions of the number of missiles for fixed 
numbers of weapons per missile. At about 100 missiles, the stability indices for singlet and triplet configurations are comparable, as are the number of weapons each would deliver on value targets.

\section{References}

1. G. Canavan, "Probability of Survival from Multiple Weapon Attacks," Los Alamos report LAUR-97-, February 1977.

2. G. Canavan, "Destabilizing Effects of Perceptions," Los Alamos report LA-UR-96-1742, May 1996.

3. G. Canavan, "Crisis Stability Indices for Adaptive Two-Layer Defenses," S. Erickson, Jr. ed., Military Modeling and Management (USA, Operations Society of America, 1991), pp. 95-125.

4. G. Canavan, "Destabilizing Effects of Perceptions," op. cit.

5. G. Canavan, "Stability at Symmetric Low Force Levels," Los Alamos report LA-UR-96-1631, May 1996.

6. G. Kent and R. DeValk, "Strategic Defenses and the Transition to Assured Survival," RAND Report R-3369-AF, October, 1986.

7. G. Canavan, "Stability at Symmetric Low Force Levels," op. cit.

8. G. Canavan, "Impact of Differing Metrics on Crisis Stability Analyses," A. Zichichi ed., International Seminar on Nuclear War and Planetary Emergencies, 18th Session: Global Stability Through Disarmament (London, World Scientific, 1993).

9. A. Piontkowsky and A. Skorokhodov, "A New Paradigm of Strategic Stability: From MADStability Toward Map-Stability," A. Zichichi ed., International Seminar on Nuclear War and Planetary Emergencies, 18th Session: Global Stability Through Disarmament (London, World Scientific, 1993); Strategic Studies Centre, Moscow Russia Report, 1993. 


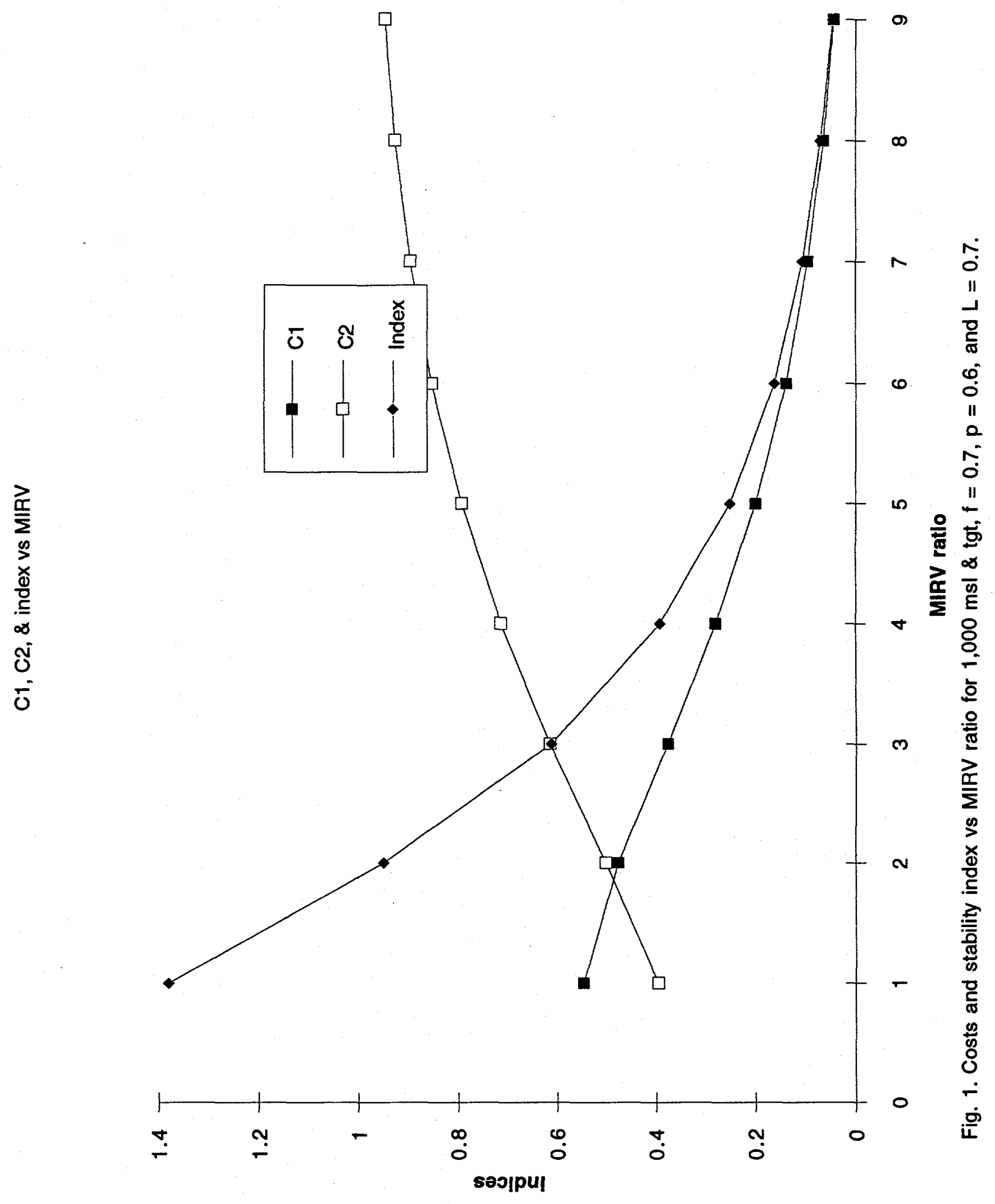


$\mathrm{C} 1, \mathrm{C} 2$, and index vs fract

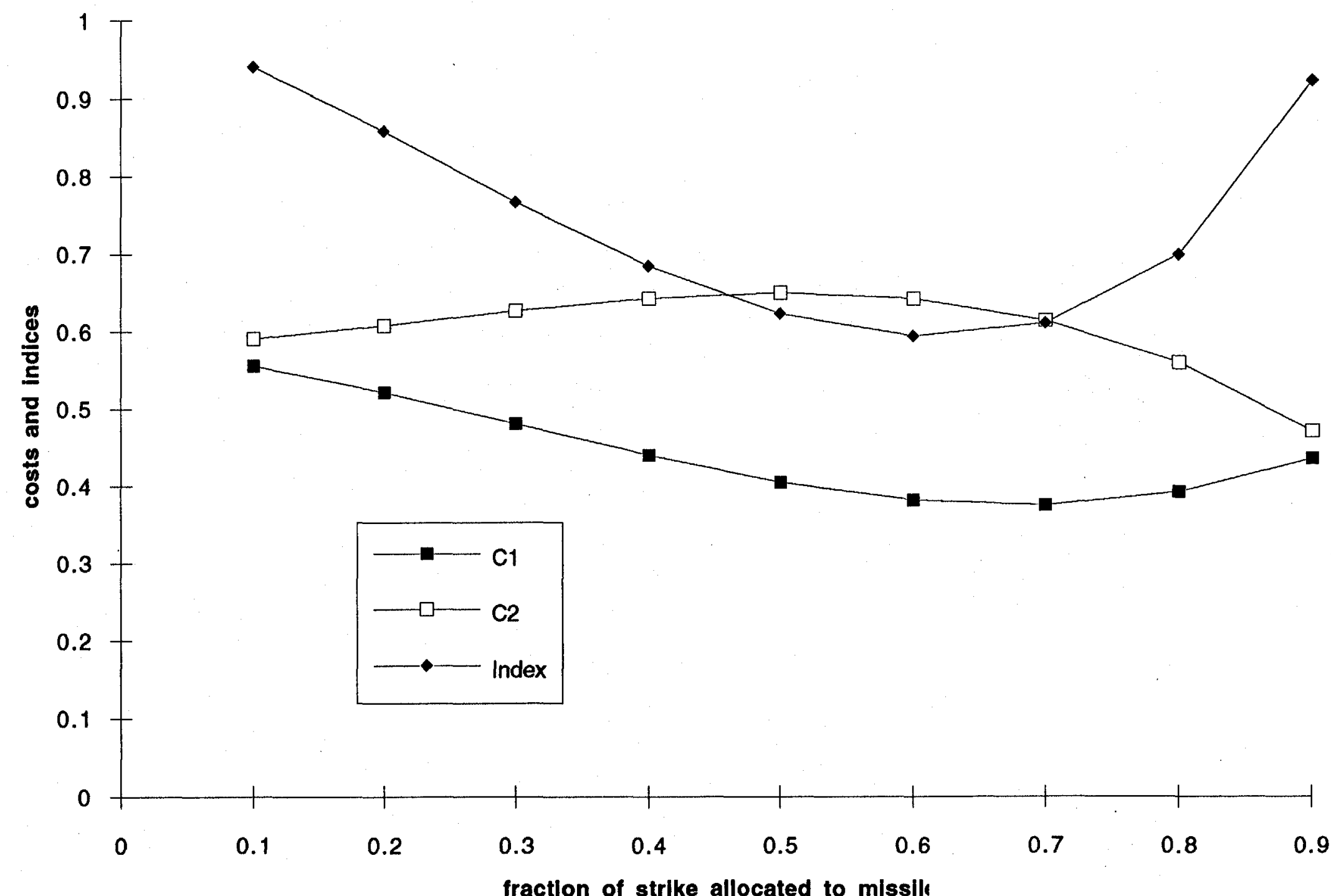

Fig. 2. Costs and indices as functions of fraction of strike allocated to 1000 missiles $(m=3, p=.6,1000$ tgts). 


\section{indices vs $L$}

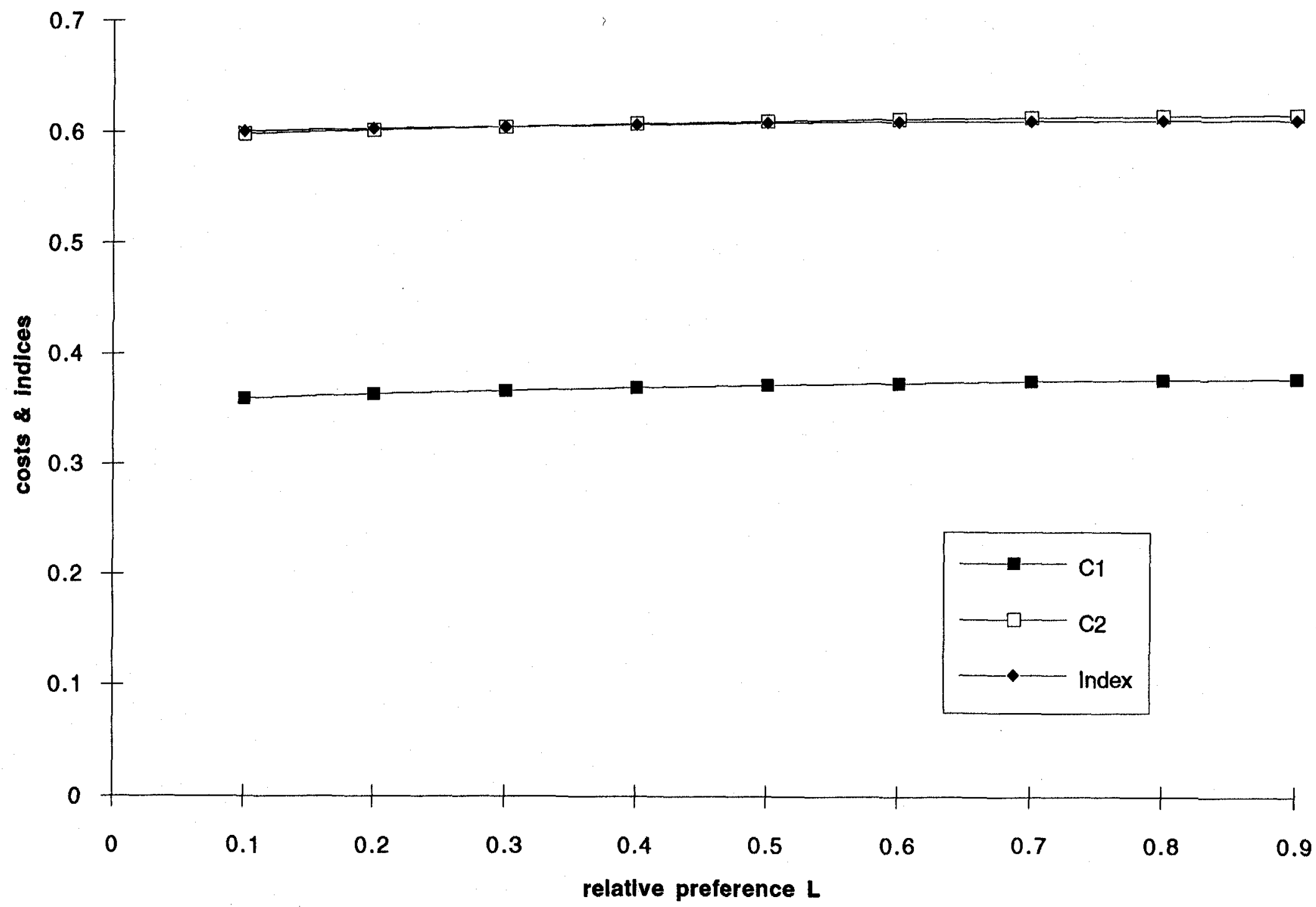

Fig. 3. Costs and indices vs relative damage preference for 3 MIRV 1000 missiles, 1,000 targets, and $p=.6$. 
incides vs $p$

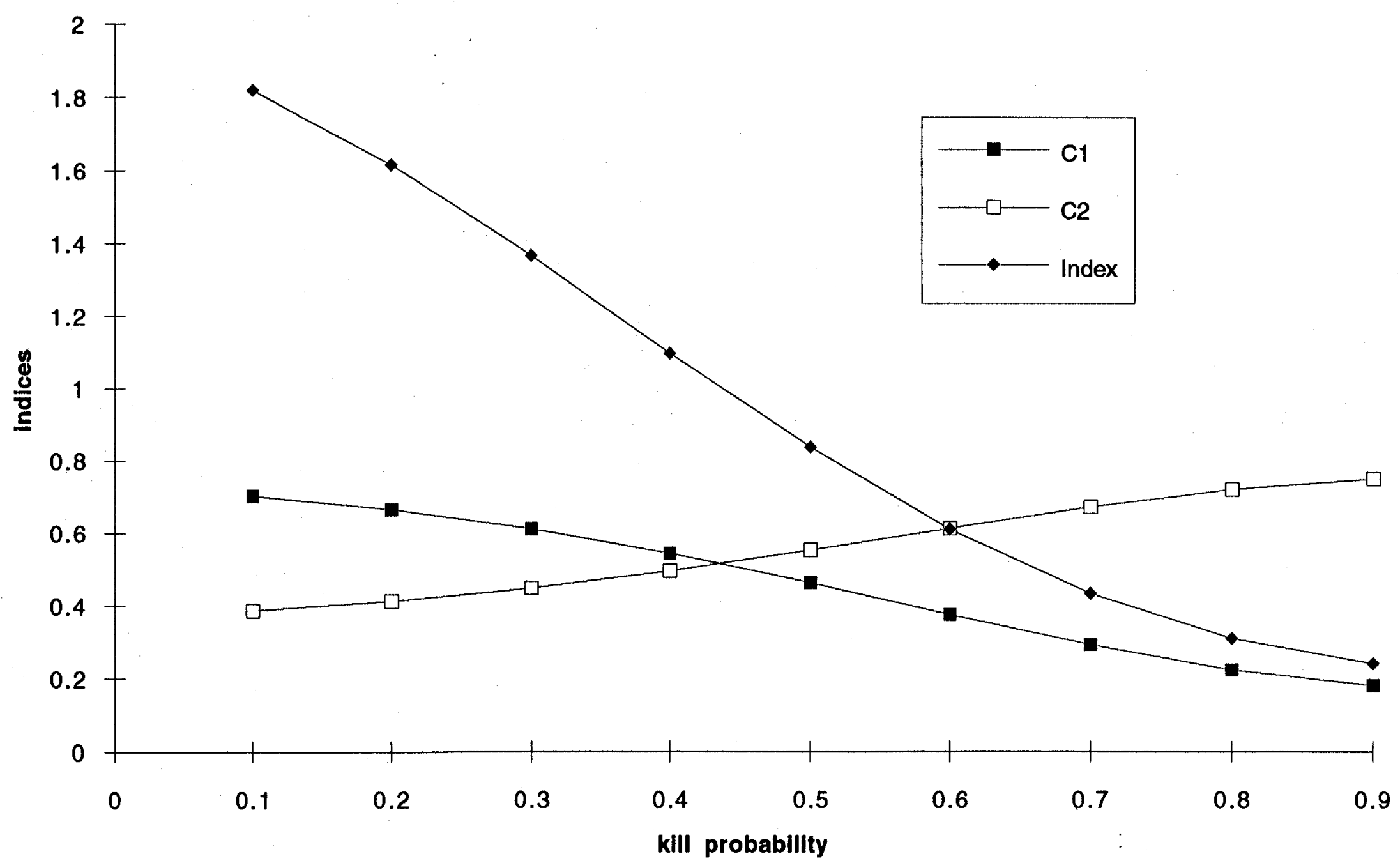

Fig. 4. Indices vs kill probability for 1000 triplet missiles. 


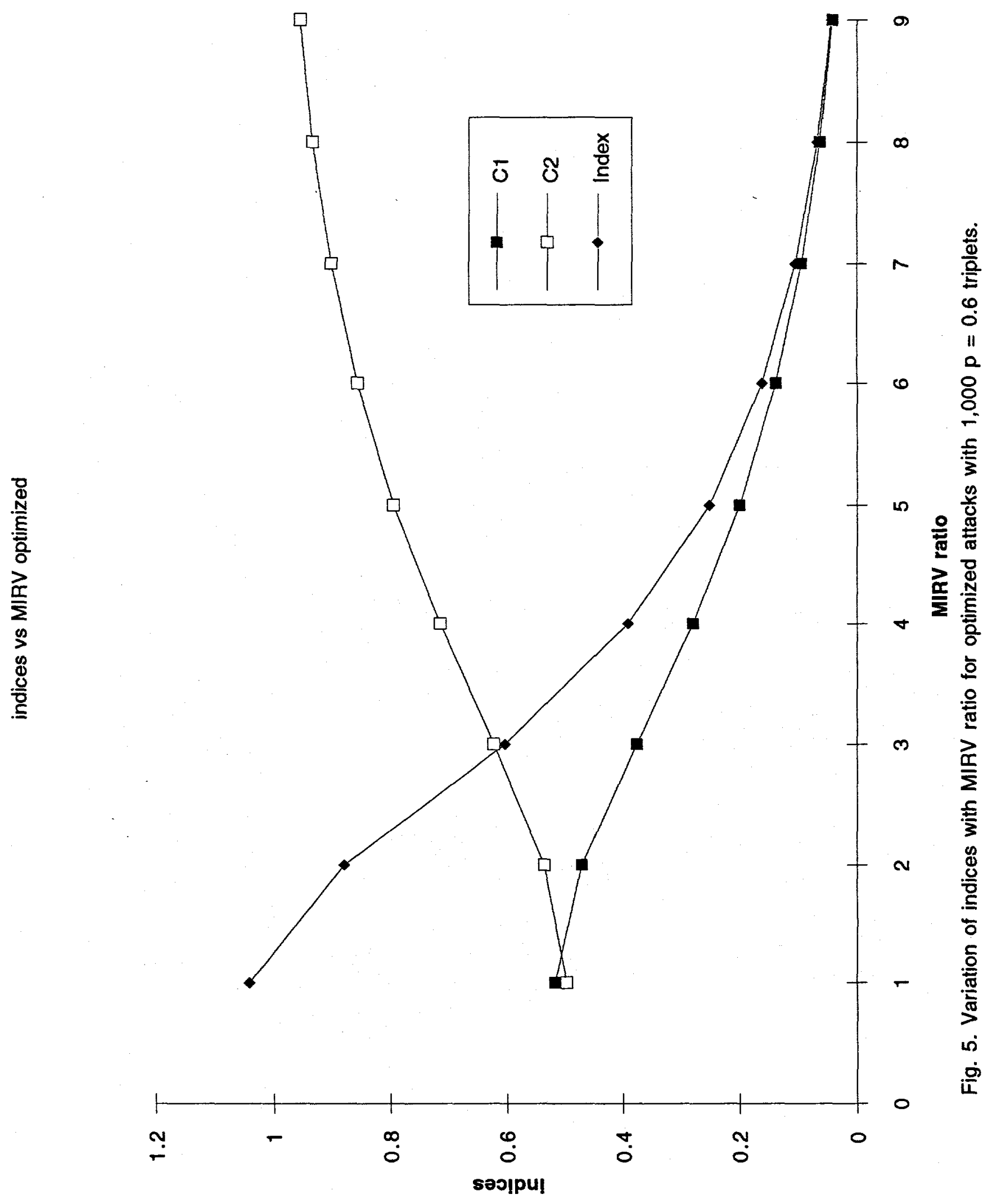




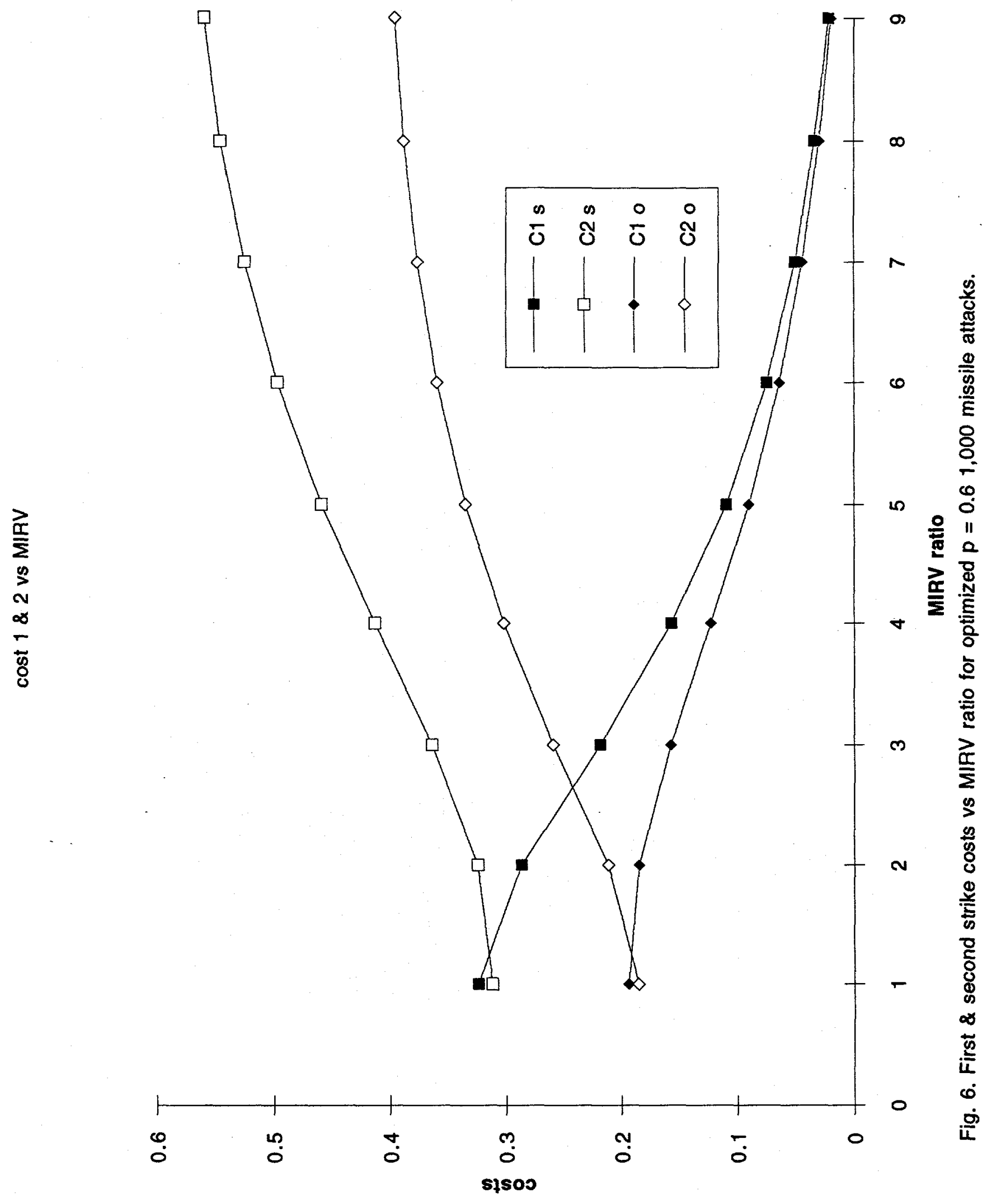




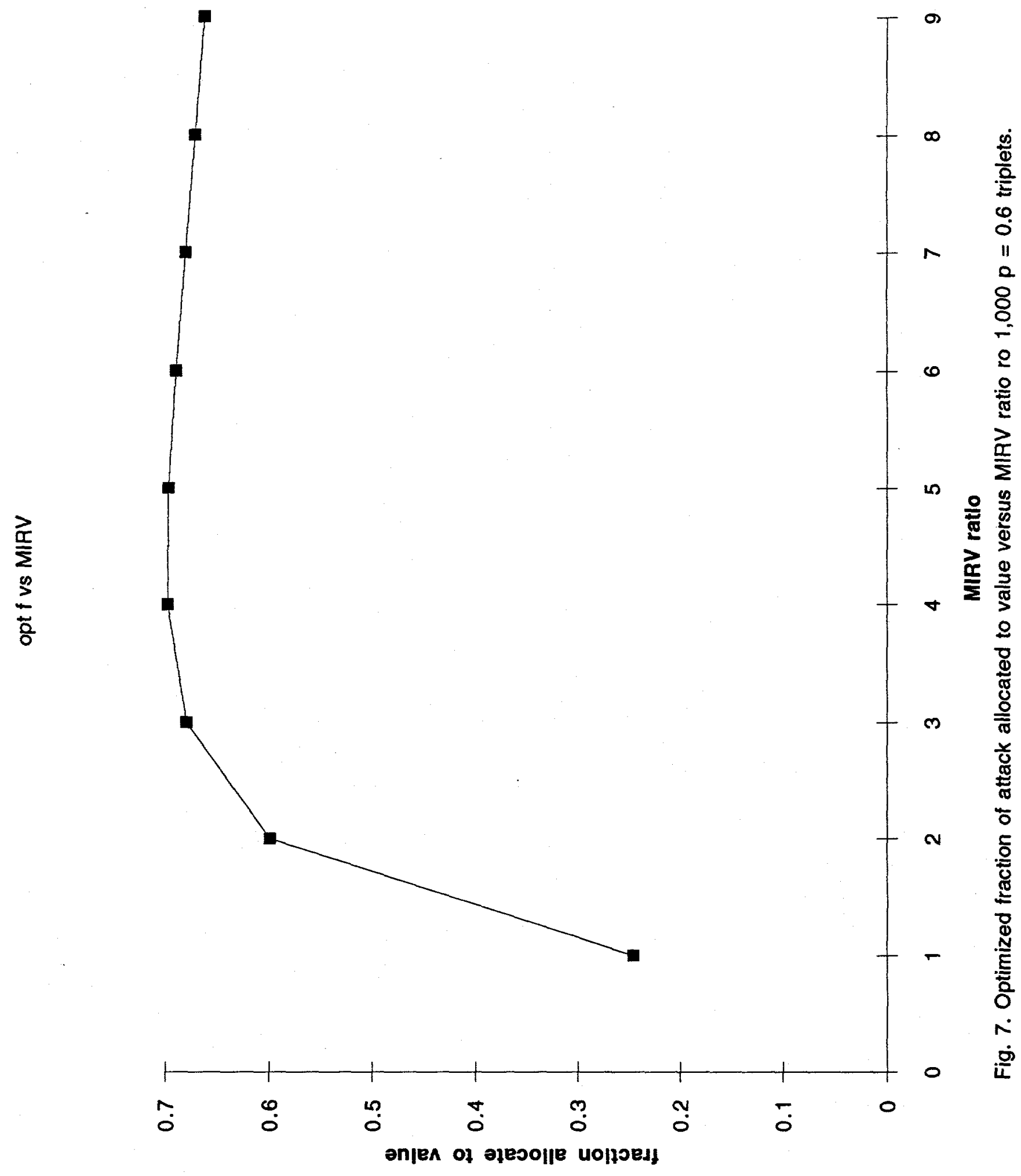




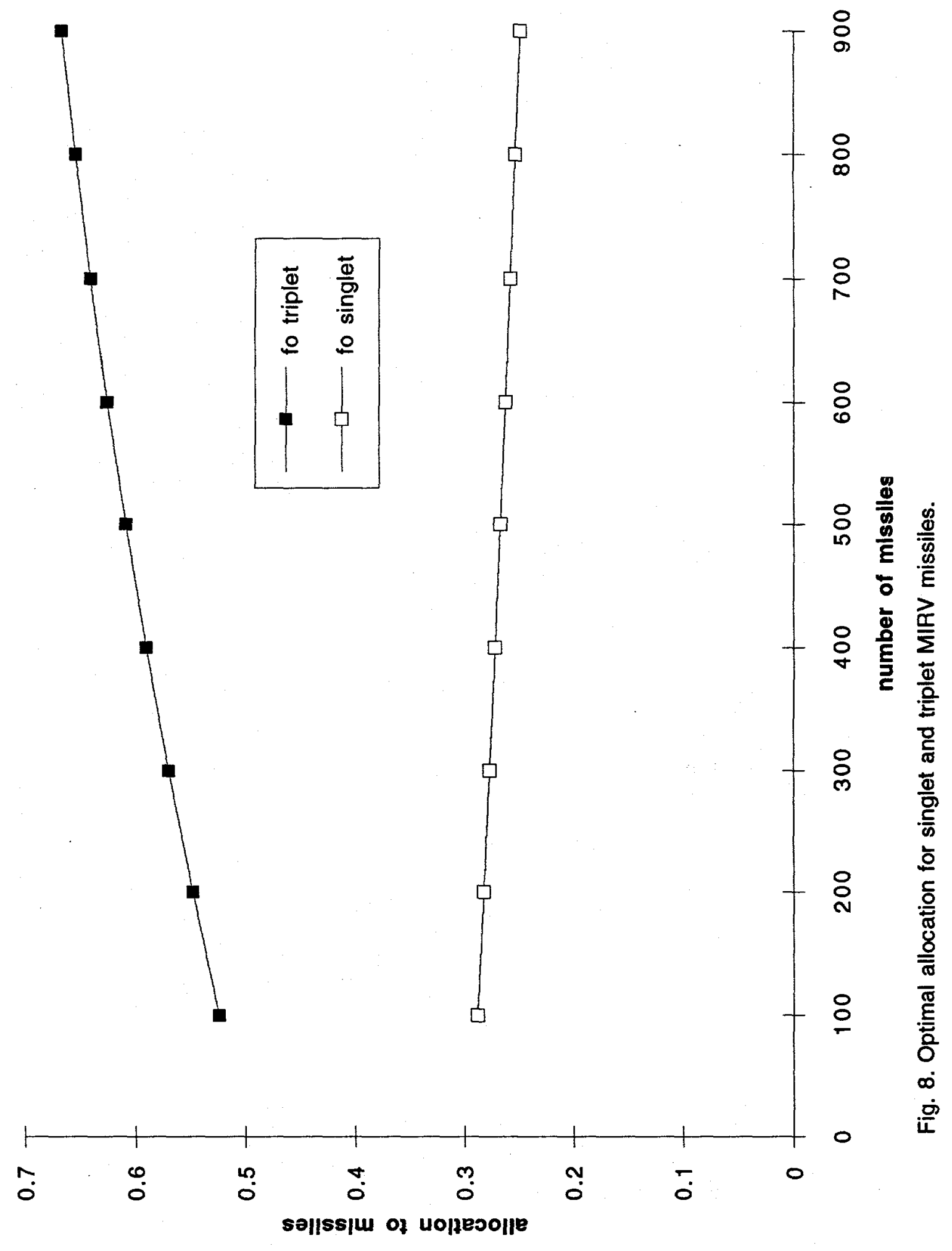






